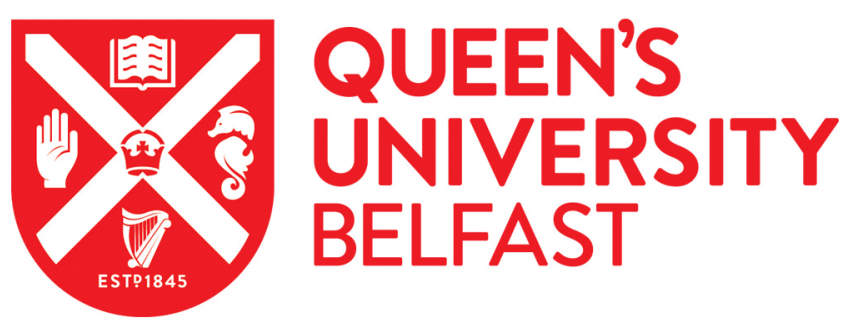

\title{
An Enhanced Robust Fault Tolerant Control Based on an Adaptive Fuzzy PID-Nonsingular Fast Terminal Sliding Mode Control for Uncertain Nonlinear Systems
}

Van, M. (2018). An Enhanced Robust Fault Tolerant Control Based on an Adaptive Fuzzy PID-Nonsingular Fast Terminal Sliding Mode Control for Uncertain Nonlinear Systems. IEEE Transactions on Mechatronics, 23(3), 1362-1371. https://doi.org/10.1109/TMECH.2018.2812244

Published in:

IEEE Transactions on Mechatronics

Document Version:

Peer reviewed version

Queen's University Belfast - Research Portal:

Link to publication record in Queen's University Belfast Research Portal

\author{
Publisher rights \\ (C) 2019 IEEE. \\ This work is made available online in accordance with the publisher's policies. Please refer to any applicable terms of use of the publisher.
}

\section{General rights}

Copyright for the publications made accessible via the Queen's University Belfast Research Portal is retained by the author(s) and / or other copyright owners and it is a condition of accessing these publications that users recognise and abide by the legal requirements associated with these rights.

Take down policy

The Research Portal is Queen's institutional repository that provides access to Queen's research output. Every effort has been made to ensure that content in the Research Portal does not infringe any person's rights, or applicable UK laws. If you discover content in the Research Portal that you believe breaches copyright or violates any law, please contact openaccess@qub.ac.uk. 


\title{
An Enhanced Robust Fault Tolerant Control Based on an Adaptive Fuzzy PID- Nonsingular Fast Terminal Sliding Mode Control for Uncertain Nonlinear Systems
}

\author{
Mien Van
}

\begin{abstract}
This paper develops an enhanced robust fault tolerant control (FTC) using a novel adaptive fuzzy PID-based nonsingular fast terminal sliding mode (AF-PID-NFTSM) control for a class of second-order uncertain nonlinear systems. In this approach, a new type of sliding surface, called PID-NFTSM, which combines the benefits of the PID and NFTSM sliding surfaces, is proposed to enhance the robustness and reduce the steady state error, whilst preserving the great property of the conventional NFTSM controller. A fuzzy approximator is designed to approximate the uncertain system dynamics and an adaptive law is developed to estimate the bound of the approximation error so that the proposed robust controller does not require a need of the prior knowledge of the bound of the uncertainties and faults and the exact system dynamics. The proposed approach is then applied for attitude control of a spacecraft. The simulation results verify the superior performance of the proposed approaches over other existing advanced robust fault tolerant controllers.
\end{abstract}

Index Terms - Fault diagnosis, fault tolerant control, highorder sliding mode control, nonlinear systems, sliding mode control.

\section{INTRODUCTION}

$\mathrm{T}$ HE recent demands of modern automatic control systems are to increase the reliability and safe operation of the systems. To complete the mission, fault diagnosis (FD) [12] and fault tolerant control (FTC) [3-5] have been developed over the past decades. Generally, FTC is classified into two classes: active fault tolerant control (AFTC) and passive fault tolerant control (PFTC). In AFTC [6-9], the system is operated based on two basic steps. In the first step, a fault diagnosis/fault detection and isolation (FD/FDI) scheme is designed to get fault information. Then, based on the received fault information, the nominal controller is adapted accordingly to change its output to compensate for the effects of faults in the system. This approach, therefore, requires an additional design of FD/FDI scheme that might increase the complexity and computational burden of the system. In addition, the two

Manuscript received July 17, 2017, revised Nov 27 2017, accepted Jan 21, 2018. (Corresponding author: Mien Van).

Mien Van is with the Institute of Research and Development, Duy Tan University, Vietnam and the College of Engineering, Mathematics and Physical Sciences, University of Exeter, United Kingdom (e-mail: vanmien1@gmail.com/m.van@exeter.ac.uk). steps operation of the AFTC may delay the fault compensational time, which may affect to the stability of the system due to the fast variation of the fault. In PFTC [10-11], a robust controller is designed to compensate the effects of faults, which is considered as an additional uncertainty in the system. The structure of the AFTC and PFTC are illustrated in Fig. 1. Since the PFTC does not need to wait for the fault information feedback from a FD/FDI scheme, it can compensate the fault effects much faster than that of the AFTC. However, the design of the PFTC has two major drawbacks: (1) it would require a prior knowledge of the bound value of the magnitude of the uncertainties and faults, and (2) since the design procedure is based on the bound value of the fault, which is the heaviest fault effects condition in the system, the PFTC would need a control technique with strong robustness.

In the literature, several robust control techniques have been developed to deal with the effects of the uncertainties and/or disturbances and faults in the system, such as PID controller [12-13], neural network controller [14], fuzzy logic controller [15-16], or sliding mode controller (SMC) [17-20]. Among them, the SMC has been shown to have stronger robustness compared to others. Due to the benefits, the SMC has been widely applied for the design of FTC [21-24]. However, the conventional SMC has several drawbacks that reduce its effectiveness for real applications such as chattering, singularity and it does not guarantee a defined finite time convergence [17]. In addition, even though the SMC has a good robustness property in front of matched uncertainties, this needs to be improved when dealing with the effects of faults to stabilize the system quickly. To obtain a defined finite time convergence, terminal sliding mode (TSM) has been studied $[25,26]$. Unlike the conventional SMC, which is designed based on a linear sliding surface, the TSM utilizes a nonlinear sliding surface, and thus it can guarantee a defined finite time convergence. Unfortunately, the conventional TSM provides a slow convergence speed and singularity phenomenon. To solve these two problems, fast terminal sliding mode (FTSM) [27] and nonsingular terminal sliding mode (NTSM) [28] have been developed separately. It can be seen that while FTSM can provide faster convergence, it has not considered solving the singularity phenomenon in the design. In contrast, the NTSM can solve the singularity problem, but, unfortunately, it possesses a slow convergence speed like the conventional 
TSM. In order to obtain both fast defined finite time convergence and singularity elimination, nonsingular fast terminal sliding mode (NFTSM) control has been developed [29-32]. Comparison between the conventional SMC and TSM in terms of defined finite time convergence property and the properties of FTSM, NTSM and NFTSM have been discussed thoroughly in [29]. However, the design of the NFTSM does not improve the robustness of the SMC and eliminate the chattering. To increase the robustness of the SMC, a hybrid system called PID-based SMC has been developed [33-38]. The idea of the PID-based SMC is to bring the advantages of the integral component of the PID controller into the design of SMC to increase its robustness. However, all the current existing PID-based SMC controllers in the literature only consider the linear sliding surface, and therefore they have the same drawbacks as the conventional SMC such as singularity and undefined finite time convergence. In a demand of real applications, there is a need to combine the properties of PID and NFTSM to obtain a defined finite time convergence and enhance the robustness of the system. However, according to the best of the author's knowledge, there have been no approaches in the literature to make this adventure. This was because, according to our observation, the combination between PID and NFTSM might increase the control order and complexity of the system (see Eq. (7)) that may lead to difficulty in reconstruction of the control law.

The remaining issue of the SMC is the chattering phenomenon. In the literature, several approaches have been proposed to eliminate the chattering, such as boundary layer method [17], disturbance observer [39], or high-order sliding mode (HOSM) control [40-45]. Among them, HOSM control is preferred to be employed rather than other techniques since it not only eliminates the chattering but also increases the precision of the system. The idea of the HOSM is to increase the order of the system such that the reconstructed discontinuous control input are under integral and therefore, the chattering is much reduced [40-45]. Similar idea to the HOSM controller, full-order sliding mode control (FOSM) has been proposed [46]. The FOSM takes the full order of the sliding variable into the design of the sliding surface, and thus a continuous reaching law can be reconstructed. In the conventional approach, the HOSM was motivated to eliminate the chattering of the conventional SMC. However, due to the great properties of both HOSM and NFTSM, there is a desire to combine the benefits of both to obtain defined finite time convergence, chattering elimination and high accuracy simultaneously. In the literature, some hybrid control methods, which combine the benefits of TSM and supper-twisting HOSM, have been developed [32]. However, the combined techniques provide new issues such as they increase the complexity of the system. In addition, the stability of the system have not been proved properly in these designs, and therefore the stability of the system may not be guaranteed for the system in some conditions. Therefore, there is a need to develop a hybrid system that integrates the properties of the HOSM into
PID and NFTSM by using a more efficient way.

Generally, the design of the PFTC would require a prior knowledge of the exact dynamic model of the system and the bound value of the uncertainties and faults [38]. However, these parameters are expensive and difficult to be obtained in advance in real applications. In order to estimate the bound value of these parameters, several simple adaptive techniques have been developed for conventional SMC [38, 47-49] and HOSM [50-51]. However, it should be noted that the amount of the chattering are proportional to the magnitude of the sliding gain. Therefore, when the magnitude of the unknown function is big, the sliding gain is slowly adapted to a big value to guarantee the existing condition of the SMC. Unfortunately, this provides a slow convergence speed and big chattering. In an attempt to approximate the unknown system model, approximation techniques based on adaptive neural networks (NN) [52-54] or fuzzy logics [55-56] have been widely developed. As a result, adaptive neural sliding modes [57-59] or adaptive fuzzy sliding modes [60-63] have been proposed. Due to the approximation capability of the NN or fuzzy logic over the simple adaptive law approaches, the convergence speed of the system is faster and the chattering is much reduced since the sliding gains just need to approximate the NN/fuzzy logic error, which is usually very small. One of the advantages of the fuzzy logic over NN is that it takes the human knowledge about the system into the design, and thus the controller could be able to provide a good tracking response. However, integrating fuzzy logic into the new hybrid system, which includes PID, NFTSM and HOSM, generates a new issue since this combination may violate the stability of the system if it is not designed properly. Therefore, this requires an appropriate design procedure and stability proof to guarantee the performance and the stability of the whole hybrid system.

In this paper, a novel robust FTC based on an adaptive fuzzy PID-based NFTSM is developed for uncertain nonlinear systems. In this approach, a new PID-NFTSM sliding surface, which integrates the great features of the PID and NFTSM sliding surfaces, is developed to enhance the robustness and reduce the steady state error of the system, whilst guaranteeing a defined finite time convergence of the state variables. In addition, different from the conventional combination between NFTSM and HOSM [32], the great property of the HOSM is integrated into the hybrid PID-NFTSM in an intelligent way without damaging the stability of the system. Moreover, by integrating an adaptive fuzzy approximator into the PIDNFTSM controller, the proposed adaptive fuzzy PID-NFTSM controller could eliminate the requirement of the prior knowledge of the bound information of the uncertainties and faults in the design. The proposed approaches can be applied for a class of second-order nonlinear systems. In this paper, we simulate the performance of the attitude control of a spacecraft as an example. The simulation results verify that the proposed adaptive fuzzy PID-NFTSM provides superior performance compared to other advanced robust control and robust FTC techniques, such as NFTSM [31], third order sliding mode 
(TOSM) [38] and FOSM [46].

The remainder of this paper is constructed as follows. Section II presents the problem formulation and notations. Section III introduces a PID-NFTSM controller. Section IV describes the design of the adaptive fuzzy PID-NFTSM. Simulation results for attitude control of a spacecraft are given in Section V. Section VI provides conclusions.

\section{II.PROBLEM STATEMENT AND NOTATIONS}

\section{A. Problem formulation}

In this paper, we consider the following general second-order nonlinear system $[23,38]$ :

$\dot{\mathrm{x}}_{1}=\mathrm{x}_{2}$

$\dot{\mathrm{x}}_{2}=\mathrm{f}(\mathrm{x})+\mathrm{G}(\mathrm{x}) \mathrm{u}^{*}+\mathrm{d}$

where the state variables of the system are $\mathrm{x}=\left(\mathrm{x}_{1}, \mathrm{x}_{2}\right)^{\mathrm{T}}$, with $\mathrm{x}_{1}=\left(x_{1}, \ldots, x_{n}\right)^{T} \in \mathfrak{R}^{n}$ and $\mathrm{x}_{2}=\left(x_{n+1}, \ldots, x_{2 n}\right)^{T} \in \mathfrak{R}^{n}$, the smooth functions $\mathrm{f}(\mathrm{x}) \in \mathfrak{R}^{n}$ and $\mathrm{G}(\mathrm{x}) \in \mathfrak{R}^{n \times m}$ denote the system dynamics with the initial values $f(0)=0$, the input component $\mathrm{u}^{*}=\left(u_{1}^{*}, \ldots, u_{m}^{*}\right) \in \mathfrak{R}^{m}$ with $m \geq n$ denotes the actuator and the component $\mathrm{d}=\left(d_{1}, \ldots, d_{n}\right)^{T} \in \mathfrak{R}^{n}$ indicates the possibly uncertainties and/or disturbances in the system.

In this paper, we consider a type of actuator fault called lossof-effectiveness (LOE) since it is usually occurred in wide practical applications [13-16, 31-32]. To describe actuator fault due to the LOE, the control input of (1) can be expressed as [23]:

$\mathrm{u}^{*}=\mathrm{u}+\Delta \mathrm{u}$

where $\Delta \mathrm{u}$ denotes the actuator faults, $\mathrm{u}^{*}$ and $\mathrm{u}$ are the actual and the designed control value, respectively.

From (1) and (2), the dynamics system (1) can be rewritten as below when one or multiple actuator faults occurs:

$$
\begin{aligned}
\dot{x}_{1} & =x_{2} \\
\dot{x}_{2} & =f(x)+G(x) u+G(x) \Delta u+d \\
& =f(x)+G(x) u+\Pi(x, \Delta u)+d
\end{aligned}
$$

where $\Pi(\mathrm{x}, \Delta \mathrm{u})=\mathrm{G}(\mathrm{x}) \Delta \mathrm{u} \in \mathfrak{R}^{n}$.

Assumption 1: The following condition is assumed for analysis in the next sections:

$$
\left\|M(\mathrm{x}, \mathrm{t})=\frac{d(\Xi(\mathrm{x}, \Delta \mathrm{u}, d))}{d t}\right\| \leq \Gamma
$$

where $\Xi(\mathrm{x}, \Delta \mathrm{u}, d)$ is a function, which will be defined later after (8), and $\Gamma$ is a constant parameter.

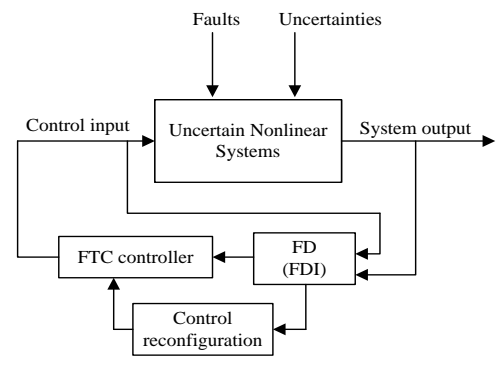

(a)

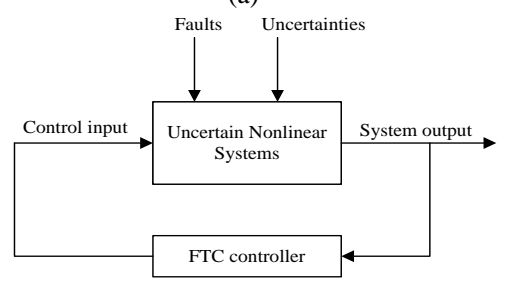

(b)

Fig.1. Structure of (a) AFTC and (b) PFTC.

The objective of this paper is to develop a strong robust FTC law $\mathrm{u}$ such that the performance of the system is always guaranteed no matter whether the existing of uncertainties, disturbance and faults.

\section{B. Notations}

The following notations have been employed across the paper to reduce the length of sentences:

$\mathrm{s}_{P I D}=\mathrm{s}_{P I D-N F T S M}, \mathrm{u}_{P I D}=\mathrm{u}_{P I D-N F T S M}$,

$\mathrm{u}_{A F}=\mathrm{u}_{\text {adaptive fuzzy PID-NFTSM }}$.

\section{DESIGN OF A ROBUST PROPORTIONAL-INTEGRAL- DERIVATIVE (PID)-NONSINGULAR FAST TERMINAL SLIDING MODE CONTROLLER}

In this subsection, we develop a robust PID-NFTSM to explore the properties of the PID and NFTSM controllers. First, a nonsingular fast terminal sliding mode (NFTSM) sliding surface is selected as [29-32]:

$\mathrm{s}_{\text {NFTSM }}=\mathrm{x}_{1}+k_{1} \mathrm{x}_{1}{ }^{[\lambda]}+k_{2} \mathrm{x}_{2}{ }^{[p / q]}$

where $k_{1} \in \mathfrak{R}^{n x n}$ and $k_{2} \in \mathfrak{R}^{n x n}$ are positive matrices, respectively, $p$ and $q$ are positive odd numbers satisfying the relation $1<p / q<2$ and $\lambda>p / q$.

Then, a PID-NFTSM sliding surface is proposed as

$\mathrm{s}_{P I D}=K_{p} \mathrm{~s}_{N F T S M}+K_{i} \int \mathrm{s}_{N F T S M}+K_{d} \frac{d \mathrm{~s}_{N F T S M}}{d t}$

where the derivative of the NFTSM sliding surface is computed as

$\frac{d \mathrm{~s}_{N F T S M}}{d t}=\mathrm{x}_{2}+k_{1} \lambda\left|\mathrm{x}_{1}\right|^{\lambda-1} \cdot \mathrm{x}_{2}+k_{2} \frac{p}{q}\left|\mathrm{x}_{2}\right|^{(p / q)-1} \cdot \dot{\mathrm{x}}_{2}$

From (6) we can see that the proposed sliding surface has a form of NFTSM and PID sliding surfaces. Therefore, the 
proposed sliding surface possesses the benefits of both approaches such as fast transient response, lower steady state error, nonsingular fast defined finite time convergence. These properties are very significant and essential for FTC systems since they can compensate the fault effects and stabilize the system much faster. In addition, looking up to (7) we can see that it has a form of FOSM and therefore the chattering problem can be eliminated as the same manner to the FOSM. Hence, the proposed sliding surface in (6) allows the system preserving the great properties of the PID, NFTSM and HOSM simultaneously.

Combining the results in (3), (6) and (7), we have:

$$
\begin{aligned}
& \mathrm{s}_{P I D}=K_{p} \mathrm{~s}_{N F T S M}+K_{i} \int \mathrm{s}_{N F T S M} \\
& +K_{d}\left(\begin{array}{l}
\mathrm{x}_{2}+k_{1} \lambda\left|\mathrm{x}_{1}\right|^{\lambda-1} \cdot \mathrm{x}_{2} \\
+k_{2} \frac{p}{q}\left|\mathrm{x}_{2}\right|^{(p / q)-1} \cdot\left(\begin{array}{l}
\mathrm{f}(\mathrm{x})+\mathrm{G}(\mathrm{x}) \mathrm{u} \\
+\Pi(\mathrm{x}, \Delta \mathrm{u})+\mathrm{d}
\end{array}\right)
\end{array}\right) \\
& =K_{p} \mathrm{~s}_{N F T S M}+K_{i} \int \mathrm{s}_{N F T S M}+K_{d}\left(\begin{array}{l}
\mathrm{x}_{2}+ \\
k_{1} \lambda\left|\mathrm{x}_{1}\right|^{\lambda-1} \cdot \mathrm{x}_{2}
\end{array}\right) \\
& +K_{d} k_{2} \frac{p}{q}\left|\mathrm{x}_{2}\right|^{(p / q)-1} \cdot(\mathrm{f}(\mathrm{x})+\mathrm{G}(\mathrm{x}) \mathrm{u}+\Pi(\mathrm{x}, \Delta \mathrm{u})+\mathrm{d}) \\
& =F\left(\mathrm{~s}_{\text {NFTSM }}, \mathrm{x}\right)+\Xi(\mathrm{x}, \Delta \mathrm{u}, d)+\chi\left(\mathrm{x}_{2}\right) \cdot(\mathrm{f}(\mathrm{x})+\mathrm{G}(\mathrm{x}) \mathrm{u})
\end{aligned}
$$

where $\chi\left(\mathrm{x}_{2}\right)=K_{d} k_{2} \frac{p}{q}\left|\mathrm{x}_{2}\right|^{(p / q)-1}$,

$$
\begin{aligned}
F\left(\mathrm{~s}_{\text {NFTSM }}, \mathrm{x}\right)=K_{p} \mathrm{~s}_{\text {NFTSM }} & +K_{i} \int \mathrm{s}_{\text {NFTSM }} \\
& +K_{d}\left(\mathrm{x}_{2}+k_{1} \lambda\left|\mathrm{x}_{1}\right|^{\lambda-1} \cdot \mathrm{x}_{2}\right), \text { and }
\end{aligned}
$$

$\Xi(\mathrm{x}, \Delta \mathrm{u}, d)=\chi\left(\mathrm{x}_{2}\right) \cdot(\Pi(\mathrm{x}, \Delta \mathrm{u})+\mathrm{d})$ denotes the unknown component in the system.

To obtain the desired system performance, the following controller is proposed for the system (3):

$$
\mathrm{u}_{P I D}=-\mathrm{G}^{+}(\mathrm{x})\left(\mathrm{u}_{e q}+\chi^{-1}\left(\mathrm{x}_{2}\right) \mathrm{u}_{r}\right)
$$

where the equivalent control is designed as

$\mathrm{u}_{e q}=\chi^{-1}\left(\mathrm{x}_{2}\right) F\left(\mathrm{~s}_{\text {NFTSM }}, \mathrm{x}\right)+\mathrm{f}(\mathrm{x})$

and, the reaching law is

$\dot{\mathrm{u}}_{r}=(\Gamma+a) \operatorname{sign}\left(\mathrm{s}_{P I D}\right)$

where the initial value of the reaching phase is selected as $u_{r}(0)=0 . \Gamma$ is a constant value, which was defined in (4), and $a$ is a small positive constant. The stability and convergence of the system is stated in Theorem 1.

Theorem 1: Consider the system (3) with the presence of the uncertainties and faults. If the proposed PID-NFTSM control law in (9)-(11) is employed for the system (3), the stability and convergence of the state variables are guaranteed.

Proof: Applying the control laws (9)-(11) to the sliding variable (8), we have

$\mathrm{s}_{P I D}=-\mathrm{u}_{r}+\Xi(\mathrm{x}, \Delta \mathrm{u}, d)$
TABLE I

SELECTED PARAMETERS OF THE CONTROLLERS

\begin{tabular}{lll}
\hline Controller & Parameters & Values \\
\hline NFTSM & $\sigma_{1}, \sigma_{2}, p, q$ & $10,5,9,7$ \\
& $\alpha, \rho_{d}, \psi$ & $1.4,20,1000$ \\
\multirow{2}{*}{ FOSM } & $k_{1}, k_{2}, \alpha_{1}, \alpha_{2}$ & $10,7,9 / 23,9 / 16$ \\
& $c, \alpha$ & $1 / 5,0.2$ \\
TOSM & $a, b, \lambda, \gamma, \varepsilon$ & $10,5,10,0.5,0.01$ \\
& $l_{d}+k_{T}, T$ & $20,0.5$ \\
PID- & $K_{p}, K_{i}, K_{d}$ & $5,100,0.5$ \\
NFTSM & $c, \alpha, \rho_{d}$ & $1 / 5,0.2,20$ \\
Adaptive & $K_{p}, K_{i}, K_{d}$ & $5,100,0.5$ \\
Fuzzy & $c, \alpha$ & $1 / 5,0.2$ \\
PID- & The parameters for & NFTSM sliding surface \\
NFTSM & are selected as same as the NFTSM controller. \\
\hline
\end{tabular}

Differentiating the sliding variable (12), we have

$\dot{\mathrm{s}}_{P I D}=-\dot{\mathrm{u}}_{r}+\frac{d(\Xi(\mathrm{x}, \Delta \mathrm{u}, d))}{d t}$

Consider the following Lyapunov function candidate

$\mathrm{V}=\frac{1}{2} \mathrm{~s}_{P I D}^{T} \mathrm{~S}_{P I D}$

Differentiating (14) and combining the results with (13), one yields

$$
\begin{aligned}
\dot{\mathrm{V}} & =\mathrm{s}_{P I D}^{T} \dot{\mathrm{s}}_{P I D} \\
& =\mathrm{s}_{P I D}^{T}\left(-\dot{\mathrm{u}}_{r}+M(\mathrm{x}, \mathrm{t})\right) \\
& =\mathrm{s}_{P I D}^{T}\left(-(\Gamma+a) \operatorname{sign}\left(\mathrm{s}_{P I D}\right)+M(\mathrm{x}, \mathrm{t})\right) \\
& =-\Gamma\left|\mathrm{s}_{P I D}\right|+M(\mathrm{x}, \mathrm{t}) \mathrm{s}_{P I D}-a\left|\mathrm{~s}_{P I D}\right| \leq-a\left|\mathrm{~s}_{P I D}\right|
\end{aligned}
$$

where $M(\mathrm{x}, \mathrm{t})$ was defined in (4). Therefore, based on the Lyapunov criterion, the stability and convergence of the system is guaranteed. This completes the proof.

Remark 1: When the PID sliding surface converges to zero, then the NFTSM sliding surface is convergent to zero. From (5), we have: $\mathrm{s}_{N F T S M}=\mathrm{x}_{1}+k_{1} \mathrm{x}_{1}{ }^{[\lambda]}+k_{2} \mathrm{x}_{2}{ }^{[p / q]}$ where $\mathrm{x}_{1}$ is the terminal attractor of the system. The defined finite time $t_{c}$ that is taken to travel from $\mathrm{x}_{1}\left(t_{r}\right) \neq 0$ to $\mathrm{x}_{1}\left(t_{r}+t_{c}\right)=0$ is given by [29]:

$$
t_{c}=\frac{\frac{p}{q}\left|\mathrm{x}_{1}\left(t_{r}\right)\right|^{1-\frac{q}{p}}}{k_{1}\left(\frac{p}{q}-1\right)} \cdot \Omega\left(\begin{array}{l}
\frac{q}{p}, \frac{\frac{p}{q}-1}{(\lambda-1) \frac{p}{q}} ; 1+\frac{\frac{p}{q}-1}{(\lambda-1) \frac{p}{q}} \\
-k_{1}\left|\mathrm{x}_{1}\left(t_{r}\right)\right|^{\lambda-1}
\end{array}\right)
$$

where $\Omega$ denotes Gauss' hypergeometric function [29]. 
TABLE II

COMPARISON IN AVERAGE TRACKING ERROR (ATE) OF THE NFTSMC, FOSMC, TOSM, PID-NFTSM AND ADAPTIVE FUZZY-PID-NFTSM WHEN THE FAULT $\triangle \mathrm{u}$ OCCURS

\begin{tabular}{lcccc}
\hline Controller & $A T E_{1}$ & $A T E_{2}$ & $A T E_{3}$ & $\sum_{1}^{3}{ }^{A}{ }^{A} E_{i}$ \\
\hline NFTSM & 1.9972 & 1.2032 & 0.6276 & 3.828 \\
FOSM & 0.2109 & 0.0673 & 0.0885 & 0.3667 \\
TOSM & 0.2074 & 0.0322 & 0.0531 & 0.2927 \\
PID-NFTSM & 0.0038 & 0.0019 & 0.0007 & 0.0064 \\
$\begin{array}{l}\text { Adaptive } \\
\begin{array}{l}\text { Fuzzy PID- } \\
\text { NFTSM }\end{array}\end{array}$ & 0.0049 & 0.0030 & 0.0016 & 0.0095 \\
\hline
\end{tabular}

IV. DESIGN OF A ROBUST ADAPTIVE FUZZY PROPORTIONALINTEGRAL-DERIVATIVE (PID)-NONSINGULAR FAST TERMINAL SLIDING MODE CONTROLLER

\section{A. Fuzzy Logic Systems}

The fuzzy logic system is developed to map an input linguistic vector $\mathrm{x}=\left(x_{1}, x_{2}, \ldots, x_{n}\right)^{T} \in \mathfrak{R}^{n}$ to an output linguistic variable $y=f(\mathrm{x}) \in \mathfrak{R}$ using a set of IF-THEN rules [55-56]. The $i$ th fuzzy IF-THEN rule can be described by

$R^{i}$ : If $x_{1}$ is $A_{1}^{i}$ and $\ldots$ and $x_{n}$ is $A_{n}^{i}$ then $y$ is $B^{i}$

where $A_{1}^{i}, A_{2}^{i}, \ldots, A_{n}^{i}$ and $B^{i}$ are fuzzy sets. The output of the fuzzy logic system is defined as

$$
y=\sum_{i=1}^{h} w_{i}\left(\prod_{j=1}^{n} \mu_{A_{j}^{i}}\left(x_{j}\right)\right) / \sum_{i=1}^{h}\left(\prod_{j=1}^{n} \mu_{A_{j}^{i}}\left(x_{j}\right)\right)=\mathrm{w}^{T} \psi(\mathrm{x})
$$

where $h$ denotes the number of total of IF-THEN rules and $w_{i}$ is the point at which $\mu_{B^{i}}\left(w_{i}\right)=1 . \mathrm{w}=\left[w_{1}, w_{2}, \ldots, w_{h}\right]^{T}$ is a vector of adjustable parameters, and $\psi(\mathrm{x})=\left[\psi_{1}(\mathrm{x}), \psi_{2}(\mathrm{x}), . ., \psi_{h}(\mathrm{x})\right]^{T}$ is a fuzzy basis vector with $\psi_{i}(\mathrm{x})$ defined as

$$
\psi_{i}(\mathrm{x})=\prod_{j=1}^{n} \mu_{A_{j}^{i}}\left(x_{j}\right) / \sum_{i=1}^{h}\left(\prod_{j=1}^{n} \mu_{A_{j}^{i}}\left(x_{j}\right)\right)
$$

The approximation capability of the fuzzy logic is described in Lemma 1.

Lemma 1 [55-56]: For any given real continuous function $\mathrm{f}(\mathrm{x})$ on a compact set $\Omega \in \mathfrak{R}^{n}$ and an arbitrary $\varepsilon>0$, there exists a fuzzy logic system $\mathrm{w}^{T} \psi(\mathrm{x})$ such that
TABLE III

COMPARISON IN MAXIMUM ERROR OF THE NFTSMC, FOSMC, TOSM, PID-NFTSM AND ADAPTIVE FUZZY-PID-NFTSM WHEN THE FAULT $\triangle \mathrm{u}$ OCCURS

\begin{tabular}{lcccc}
\hline Controller & $E_{\max 1}$ & $E_{\max 2}$ & $E_{\max 3}$ & $\sum_{1}^{3} E_{\max i}$ \\
\hline NFTSMC & 0.2276 & 0.1385 & 0.0688 & 0.4349 \\
FOSM & 0.0952 & 0.0615 & 0.0379 & 0.1946 \\
TOSM & 0.1350 & 0.0534 & 0.0100 & 0.1984 \\
$\begin{array}{l}\text { PID- } \\
\text { NFTSM }\end{array}$ & 0.0038 & 0.0021 & 0.0021 & 0.0080 \\
$\begin{array}{l}\text { Adaptive } \\
\begin{array}{l}\text { Fuzzy PID- } \\
\text { NFTSM }\end{array}\end{array}$ & 0.0053 & 0.0031 & 0.0018 & 0.0102 \\
\hline
\end{tabular}

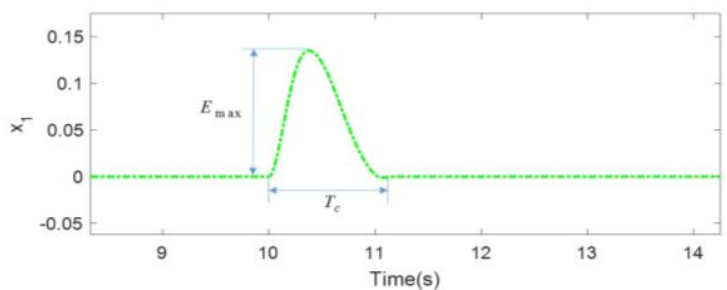

Fig. 2. Illustration of the concepts of $E_{\max }$ and $T_{c}$

$\sup _{\mathrm{x} \in \Omega}\left|\mathrm{f}(\mathrm{x})-\mathrm{w}^{T} \psi(\mathrm{x})\right| \leq \varepsilon$

where $\psi(\mathrm{x})=\left[\psi_{1}(\mathrm{x}), \psi_{2}(\mathrm{x}), \ldots, \psi_{h}(\mathrm{x})\right]^{T} / \sum_{i=1}^{h} \psi_{i}(\mathrm{x})$ is the basis function vector, $\mathrm{w}=\left[w_{1}, w_{2}, \ldots, w_{h}\right]^{T}$ is the weight vector with $h>1$ being the number of the fuzzy rules and $\psi_{i}(\mathrm{x})$ is chosen as the following form:

$\psi_{i}(\mathrm{x})=\exp \left(\frac{-\left(\mathrm{x}-\mu_{i}\right)^{T}\left(\mathrm{x}-\mu_{i}\right)}{\sigma_{i}^{2}}\right)$

where $\sigma_{i}$ is the width of the Gaussian function and $\mu_{i}=\left[\mu_{i 1}, \mu_{i 2}, \ldots, \mu_{i n}\right]^{T}$ is the center vector.

B. Robust Adaptive Fuzzy Proportional-Integral-Derivative Nonsingular Fast Terminal Sliding Mode (PID-NFTSM) Controller

In the developed PID-NFTSM, the design is based on the assumptions that the dynamic function $\mathrm{f}(\mathrm{x})$ and the bound value of the unknown function $M(\mathrm{x}, \mathrm{t})$ in the assumption 1 are known in advance. However, it is very expensive and difficult to obtain these parameters in real practical applications. To exclude the required assumptions, an adaptive fuzzy PIDNFTSM controller is developed in this subsection.

Rewriting (8), we have

$\mathrm{s}_{P I D}=F\left(\mathrm{~s}_{N F T S M}, \mathrm{x}\right)+\chi\left(\mathrm{x}_{2}\right) \cdot \mathrm{G}(\mathrm{x}) \mathrm{u}$

$$
+\chi\left(\mathrm{x}_{2}\right) \cdot \mathrm{f}(\mathrm{x})+\Xi(\mathrm{x}, \Delta \mathrm{u}, d)
$$


TABLE IV

COMPARISON IN CONVERGENCE TIME (S) AND ELAPSED TIME (ET) (S) OF THE NFTSMC, FOSMC, TOSM, PID-NFTSM AND ADAPTIVE FUZZY-PID-NFTSM WHEN THE FAULT $\Delta \mathrm{u}$ OCCURS

\begin{tabular}{lccccc}
\hline Controller & $T_{c 1}$ & $T_{c 2}$ & $T_{c 3}$ & $\sum_{1}^{3} T_{c i}$ & $\begin{array}{c}\text { ET } \\
\text { (PID=0.7) }\end{array}$ \\
\hline NFTSMC & $>20$ & $>20$ & $>20$ & $>60$ & 0.83 \\
FOSM & 4.05 & 5.90 & 2.8 & 12.75 & 0.88 \\
TOSM & 1.29 & 0.92 & 0.49 & 2.7 & 0.81 \\
$\begin{array}{l}\text { PID- } \\
\text { NFTSM }\end{array}$ & 0.35 & 0.51 & 0.15 & 1.01 & 0.90 \\
$\begin{array}{l}\text { Adaptive } \\
\begin{array}{l}\text { Fuzzy PID- } \\
\text { NFTSM }\end{array}\end{array}$ & 0.60 & 0.62 & 0.38 & 1.6 & 1.21 \\
\hline
\end{tabular}

Based on the sliding surface (22), an adaptive fuzzy PIDNFTSM controller can be designed as

$\mathrm{u}_{A F}=-\mathrm{G}^{+}(\mathrm{x}) \chi^{-1}\left(\mathrm{x}_{2}\right)\left(\mathrm{u}_{e q}+\mathrm{u}_{F Z}+\mathrm{u}_{r}\right)$

where the equivalent control is now selected as

$\mathrm{u}_{e q}=F\left(\mathrm{~s}_{N F T S M}, \mathrm{x}\right)$

Inserting the control laws (23)-(24) into (22), we have

$\mathrm{s}_{P I D}=-\mathrm{u}_{r}-\mathrm{u}_{F Z}+\chi\left(\mathrm{x}_{2}\right) \cdot \mathrm{f}(\mathrm{x})+\Xi(\mathrm{x}, \Delta \mathrm{u}, d)$

The derivative of the sliding surface (25) is

$\dot{\mathrm{s}}_{P I D}=-\dot{\mathrm{u}}_{r}-\dot{\mathrm{u}}_{F Z}+N(\mathrm{x}, t)$

where the unknown component is now represented as

$$
N(\mathrm{x}, t)=\frac{d\left(\chi\left(\mathrm{x}_{2}\right) \cdot \mathrm{f}(\mathrm{x})+\Xi(\mathrm{x}, \Delta \mathrm{u}, d)\right)}{d t}
$$

According to (20), the unknown component can be described in terms of the output of a fuzzy logic system

$$
N(\mathrm{x}, t)=\mathrm{w}^{*}(t)^{T} \psi(\mathrm{x})+\xi
$$

where $\mathrm{w}^{*}$ is the optimal weight of the fuzzy logic and $\xi$ is the approximation error. The fuzzy approximation error $\xi$ is assumed to be bounded by $\xi \leq \mathrm{K}$, where $\mathrm{K}$ is an unknown constant.

The fuzzy logic and reaching laws in (23) are now designed as

$\dot{\mathrm{u}}_{F Z}=\hat{\mathrm{w}}(t)^{T} \psi(\mathrm{x})$

$\dot{\mathrm{u}}_{r}=(\hat{K}+a) \operatorname{sign}\left(\mathrm{s}_{P I D}\right)$

where $\hat{\mathrm{w}}$ and $\hat{K}$ are the estimation of the optimal weight $\mathrm{w}^{*}$ and the bound value $\mathrm{K}$, respectively. They are updated as the following laws:

$$
\begin{aligned}
& \dot{\hat{K}}=\frac{1}{c}\left|\mathrm{~s}_{P I D}\right| \\
& \dot{\hat{\mathrm{w}}}=\frac{1}{\alpha} \mathrm{s}_{P I D} \psi(\mathrm{x})
\end{aligned}
$$

where $c$ and $\alpha$ are the constant adaptive rates. It can be seen that the bigger the adaptive gains are the faster convergence is obtained. However, the large gains might lead to overestimated of the desired values. In practice, these values are usually chosen based on experiments. However, the values chosen based on the experiments are usually not optimal. Hence, there is a desire to investigate a tuning mechanism to tune the adaptive rates such that the system can get a good approximation response. This will be studied in our future works.

Adding the results in (28)-(30) into (26), we have

$\dot{\mathrm{s}}_{P I D}=-(\hat{K}+a) \operatorname{sign}\left(\mathrm{s}_{P I D}\right)-\tilde{\mathrm{w}}(t)^{T} \psi(\mathrm{x})+\xi$

where $\tilde{\mathrm{w}}=\mathrm{w}^{*}-\hat{\mathrm{w}}$ is the fuzzy logic weight approximation error. The stability and convergence of the system is stated in Theorem 2 .

Theorem 2: Consider an uncertain nonlinear system described as in (3) and the proposed sliding surface in (5). If the proposed adaptive fuzzy PID-NFTSM controller in (23), (29) and (30) with the adaptive laws (31) and (32) is employed to control the system (3), then the stability of the system and the convergence of the sliding surface is guaranteed.

Proof: Consider the following Lyapunov function

$\mathrm{V}=\frac{1}{2} \mathrm{~s}_{P I D}^{T} \mathrm{~S}_{P I D}+\frac{1}{2} c \tilde{K}^{T} \tilde{K}+\frac{1}{2} \alpha \tilde{\mathrm{w}}^{T} \tilde{\mathrm{w}}$

where $\tilde{K}=\hat{K}-\mathrm{K}$ is the adaptive gain error.

Differentiating the Lyapunov function (34) and combining the obtained result with the result in (26) and the adaptive laws (31) and (32), we have

$$
\begin{aligned}
& \mathrm{V}=\mathrm{s}_{P I D}^{T} \dot{\mathrm{s}}_{P I D}+c \tilde{K}^{T} \dot{\tilde{K}}+\alpha \tilde{\mathrm{w}}^{T} \dot{\tilde{\mathrm{w}}} \\
&=\mathrm{s}_{P I D}^{T}\left(-(\hat{K}+a) \operatorname{sign}\left(\mathrm{s}_{P I D}\right)-\tilde{\mathrm{w}}(t)^{T} \psi(\mathrm{x})+\xi\right) \\
&+c(\hat{K}-\mathrm{K}) \dot{\hat{K}}+\alpha \tilde{\mathrm{w}}^{T} \dot{\hat{\mathrm{w}}} \\
&= \mathrm{s}_{P I D}^{T}\left(-(\hat{K}+a) \operatorname{sign}\left(\mathrm{s}_{P I D}\right)-\tilde{\mathrm{w}}(t)^{T} \psi(\mathrm{x})+\xi\right) \\
&+(\hat{K}-\mathrm{K})\left|\mathrm{s}_{P I D}\right|+\tilde{\mathrm{w}}^{T} \mathrm{~s}_{P I D} \psi(\mathrm{x}) \\
&=-\hat{K}\left|\mathrm{~s}_{P I D}\right|-a\left|\mathrm{~s}_{P I D}\right|-\mathrm{s}_{P I D}^{T} \tilde{\mathrm{w}}(t) \psi(\mathrm{x})+\xi \mathrm{s}_{P I D}^{T} \\
& \quad+(\hat{K}-\mathrm{K})\left|\mathrm{s}_{P I D}\right|+\tilde{\mathrm{w}}^{T} \mathrm{~s}_{P I D} \psi(\mathrm{x}) \\
&=-a\left|\mathrm{~s}_{P I D}\right|+\xi \mathrm{s}_{P I D}^{T}-\mathrm{K}\left|\mathrm{s}_{P I D}\right| \\
& \leq-a\left|\mathrm{~s}_{P I D}\right|
\end{aligned}
$$

Therefore, based on the Lyapunov criterion, the stability and convergence of the system is guaranteed. This completes the proof.

Remark 2: In this paper, we employ the following secondorder exact differentiation proposed in [45] to estimate the parameters of position, velocity and acceleration, which are required to implement the controller. 


$$
\begin{aligned}
& \dot{z}_{0}=v_{0} \\
& v_{0}=-m_{1}\left|z_{0}-\mathrm{x}_{1}\right|^{2 / 3} \operatorname{sign}\left(z_{0}-\mathrm{x}_{1}\right)+z_{1} \\
& \dot{z}_{1}=v_{1} \\
& v_{1}=-m_{2}\left|z_{1}-v_{0}\right|^{1 / 2} \operatorname{sign}\left(z_{1}-v_{0}\right)+z_{2} \\
& \dot{z}_{2}=-m_{3} \operatorname{sign}\left(z_{2}-v_{1}\right) .
\end{aligned}
$$

Remark 3: It can be seen from (11) and (30) that the reconstructed discontinuous control input are under integral and therefore, the chattering is reduced but not totally be eliminated. The magnitude of chattering is proportional to the magnitude of the sliding gain $\Gamma$ in (11) or $\hat{K}$ in (30). Since the gain $\Gamma$ is chosen as in (4) while $\hat{K}$ is chosen to be bigger than the fuzzy approximation error, the value $\hat{K}$ is much smaller than $\Gamma$, and consequently, the chattering generated by (30) is much smaller than the one generated by (11). As a result, the chattering of the adaptive fuzzy PID-NFTSM is much smaller than the PID-NFTSM. However, it is obvious to find out that the employed of fuzzy approximator will increase the computational burden of the system.

\section{V.RESULTS AND DISCUSSIONS}

In order to verify the superior performance, we apply the proposed method to control attitude of a spacecraft. The dynamics system of a spacecraft can be described as the similar form as in [38], where the system dynamics function is $\mathrm{f}(\mathrm{x})=\left[f_{1}(\mathrm{x}), f_{2}(\mathrm{x}), f_{3}(\mathrm{x})\right]^{T}, \quad$ where $\quad \mathrm{x}_{1}=\left(x_{1}, x_{2}, x_{3}\right)^{T}$ $=(\phi, \theta, \psi)^{T}, \quad \mathrm{x}_{2}=\left(x_{4}, x_{5}, x_{6}\right)^{T}=(\dot{\phi}, \dot{\theta}, \dot{\psi})^{T}$, and $\mathrm{x}=\left(\mathrm{x}_{1}, \mathrm{x}_{2}\right)^{\mathrm{T}}$, $\mathrm{u}=\left(u_{1}, u_{2}, u_{3}, u_{4}\right)^{T}, \quad$ and $\quad \mathrm{d}=\left[d_{1}, d_{2}, d_{3}\right]^{T} . \quad$ The three parameters $\phi, \theta$, and $\psi$ and the dynamic smooth functions $f(x)$ and $G(x)$ are provided as in [38]. In order to generate the simulation, the initial values of the position and velocity are assumed as $x(0)=[-0.7,-0.07,1.5,0.3,1.3,-0.2]^{T}$ and the disturbance is assumed as $\mathrm{d}=0.5[\sin (t), \cos (2 t), \sin (3 t)]^{T}$. In this simulation, we consider abrupt fault only since its effects in the system are much stronger than that of the incipient fault. To simulate the effects of an abrupt fault in the system, we generate a fault function $\Delta \mathrm{u}_{F}=\left[-0.5 u_{1}(10 s), 3 \sin (t)+2 \cos (t)+10(20 s), 0,0\right]^{T} . \quad$ It means that we assume the fault $\Delta u_{F 1}=-0.5 u_{1}$ (the first actuator loss $50 \%$ its effectiveness) occurs from $10 \mathrm{~s}$, and the fault $\Delta \mathrm{u}_{F 2}=3 \sin (t)+2 \cos (t)+10$ occurs in the second actuator from the time 20s. The third and fourth actuators are assumed to be normal. In addition, we compare the performances of the proposed PID-NFTSM and Adaptive Fuzzy PID-NFTSM with the advanced robust controller based on FOSM [46] and two robust FTCs based on NFTSM [31] and TOSM [38]. The parameters of these controllers are selected as in Table I. The set of membership functions of the
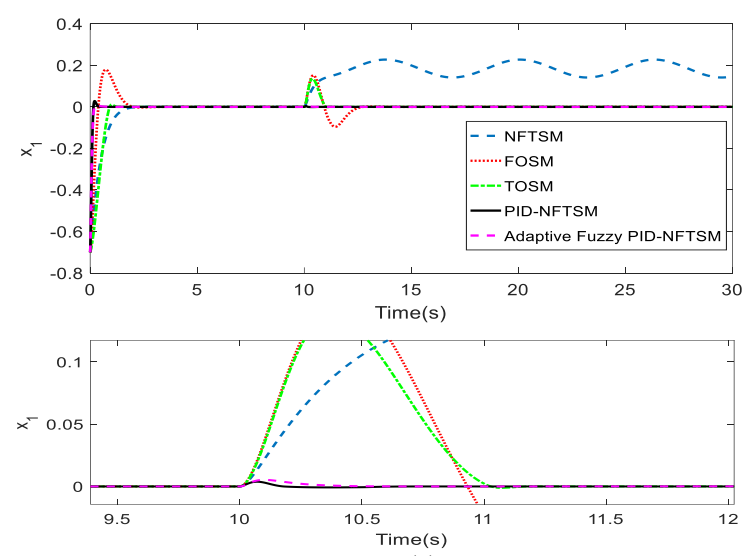

(a)
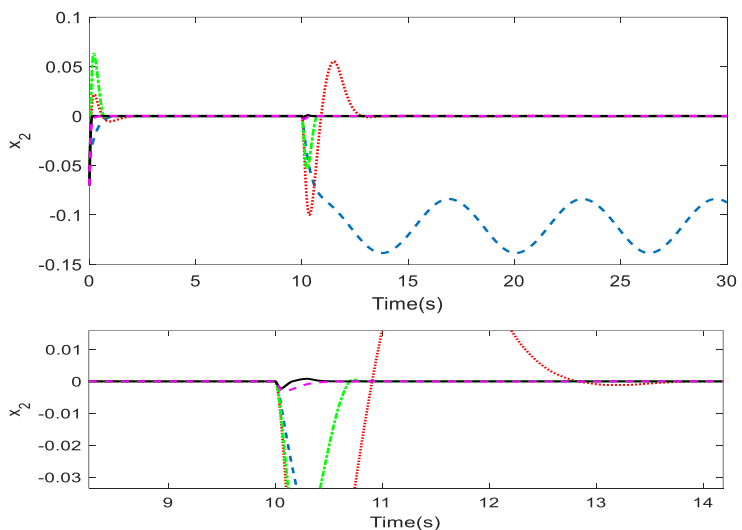

(b)
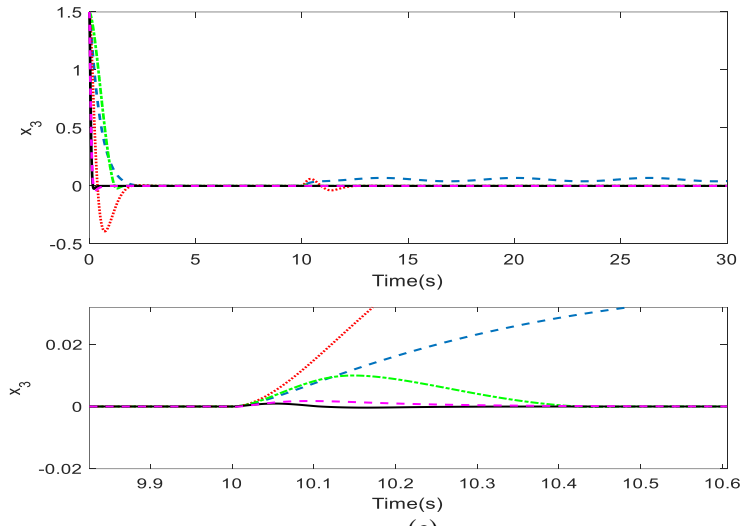

(c)

Fig. 3. Time history of system states $x_{1}, x_{2}, x_{3}$ under the effect of the generated fault

fuzzy logic in the Adaptive Fuzzy PID-NFTSM are selected as follows:

$\mu_{A_{j}^{1}}=\exp \left(-\left(x_{i}+7\right)^{2} / 4\right), \mu_{A_{j}^{2}}=\exp \left(-\left(x_{i}+5\right)^{2} / 4\right)$,

$\mu_{A_{j}^{3}}=\exp \left(-\left(x_{i}+3\right)^{2} / 4\right), \mu_{A_{j}^{4}}=\exp \left(-\left(x_{i}+1\right)^{2} / 4\right)$

$\mu_{A_{j}^{5}}=\exp \left(-\left(x_{i}+0\right)^{2} / 4\right), \mu_{A_{j}^{6}}=\exp \left(-\left(x_{i}-1\right)^{2} / 4\right)$, 

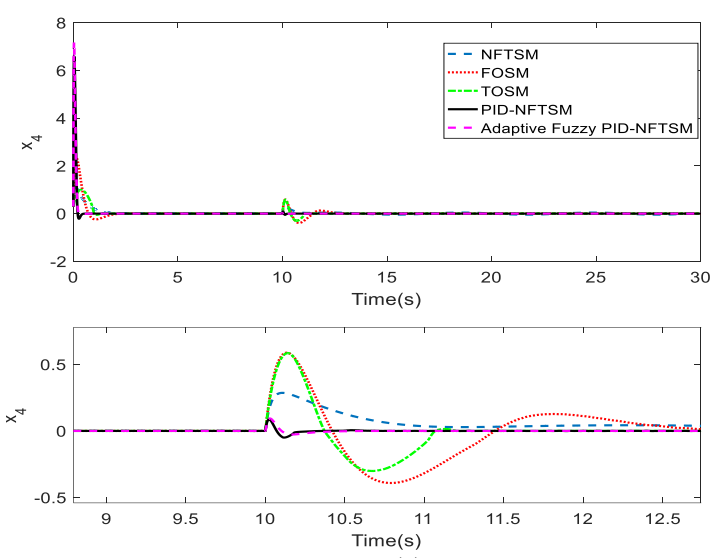

(a)
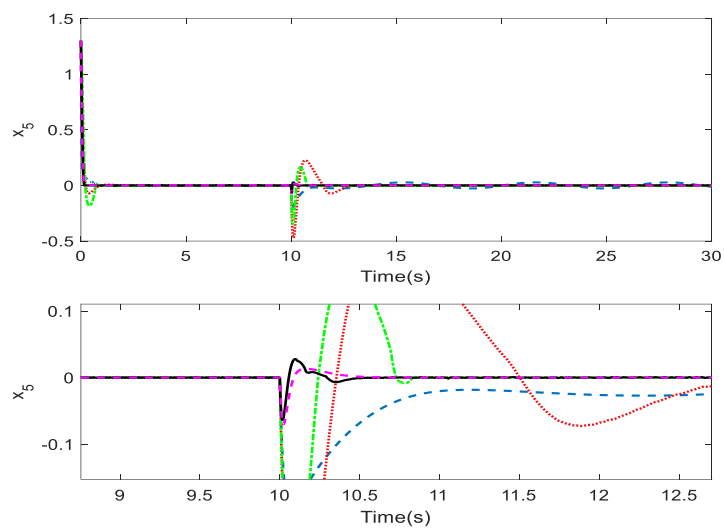

(b)
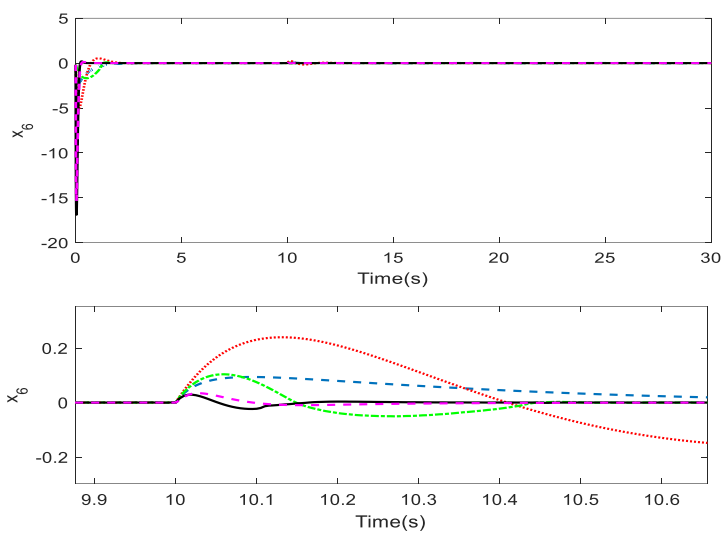

(c)

Fig. 4. Time history of system states $x_{4}, x_{5}, x_{6}$ under the effect of the generated fault

$$
\begin{aligned}
& \mu_{A_{j}^{7}}=\exp \left(-\left(x_{i}-3\right)^{2} / 4\right), \quad \mu_{A_{j}^{8}}=\exp \left(-\left(x_{i}-5\right)^{2} / 4\right), \\
& \mu_{A_{j}^{9}}=\exp \left(-\left(x_{i}-7\right)^{2} / 4\right) .
\end{aligned}
$$

For the sake of comparison, the average tracking error (ATE), maximum position tracking error $\left(E_{\max }\right)$, and convergence time $\left(T_{c}\right)$ of the system under these controllers are also reported in Tables II, III and IV, respectively. The ATE used in this paper is defined as below:
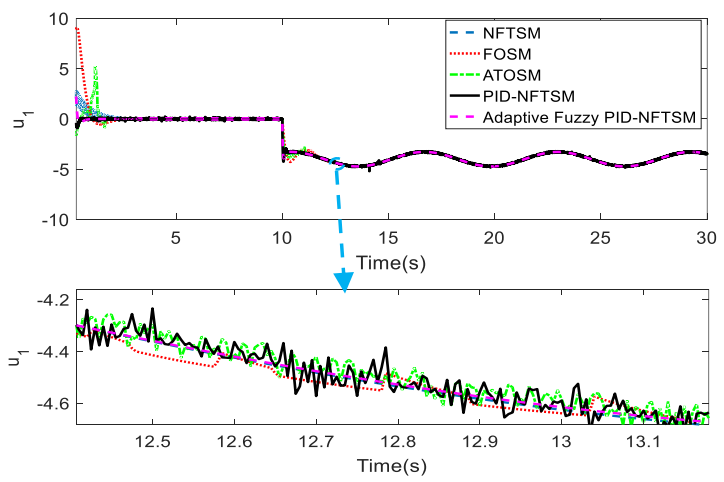

(a)
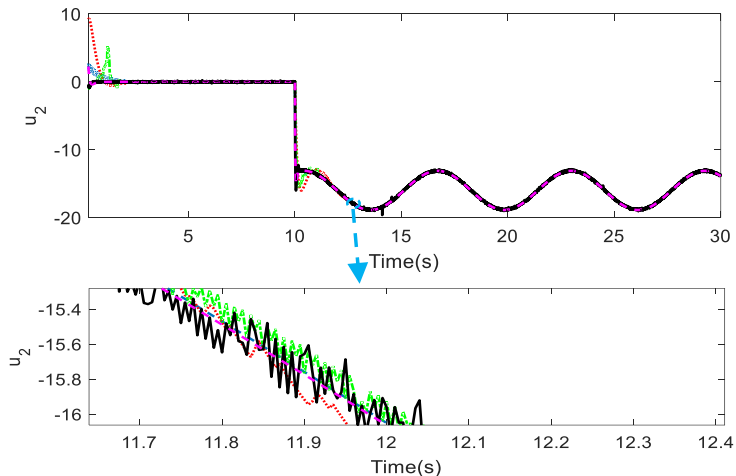

(b)
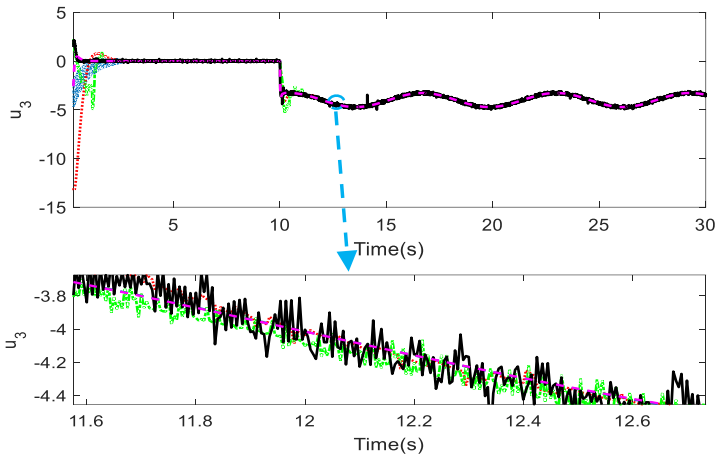

(c)

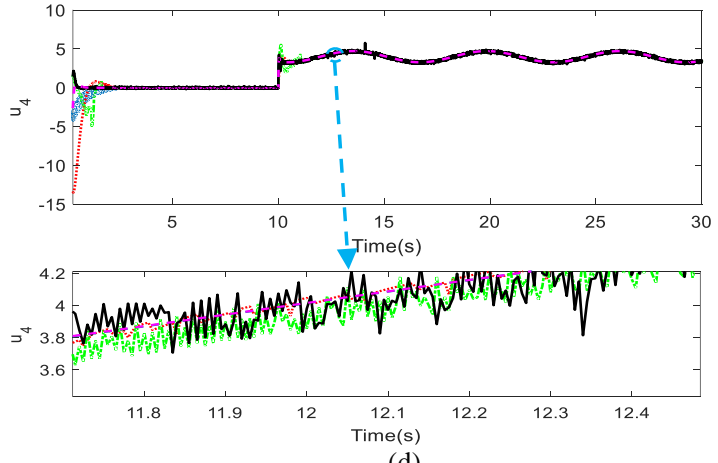

(d)

Fig. 5. Time histories of four control inputs.

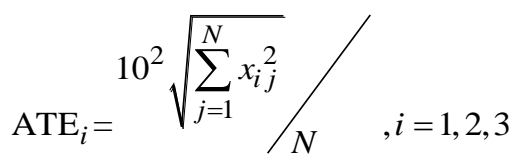

where $N$ is the number of sampling point. The maximum position tracking error $\left(E_{\max }\right)$, and the convergence time 
$\left(T_{c}\right)$ are computed as illustrated in Fig. 2. The tracking performance of the system under the inputs of the five controllers, NFTSM, FOSM, TOSM, PID-NFTSM and Adaptive Fuzzy PID-NFTSM are shown in Figs. 3, 4 and 5.

Fig. 3 shows the position tracking performance of these controllers. From the Fig. 3 we can see that the NFTSM has less robustness compared to the other four controllers. The proposed PID-NFTSM and Adaptive Fuzzy PID-NFTSM controllers provide better performance than the FOSM and TOSM controllers. Particularly, as shown in Table II (column 4), the sum of ATE of the NFTSM is 3.828, while for FOSM is 0.3667. The controllers TOSM, PID-NFTSM and Adaptive Fuzzy PID-NFTSM provide lower tracking error than the NFTSM and FOSM and their values are 0.2927, 0.0064 and 0.0095, respectively. According to the Table III (column 4), the maximum error of the PID-NFTSM (0.0080) and Adaptive Fuzzy PID-NFTSM (0.0102) are lower than the NFTSM (0.4349), FOSM (0.1946) and TOSM (0.1984). Moreover, according to Table IV (column 4), the convergence time of the PID-NFTSM (1.01) and the Adaptive Fuzzy PID-NFTSM (1.6) are faster than the NFTSM (>60), FOSM (12.75) and the

TOSM (2.7). Therefore, according to the above results we can conclude that the proposed PID-NFTSM and Adaptive Fuzzy PID-NFTSM provide better performance than the NFTSM, FOSM and TOSM controllers. Unsurprisingly, the PIDNFTSM provides higher performance compared to the Adaptive Fuzzy PID-NFTSM since it was designed based on the assumption that the system dynamics and the bound value of the uncertainties and faults were known in advance and the sliding gain was chosen as a big value, which generates a bigger chattering; this will be shown later in Fig. 5. The comparison results between PID-NFTSM and NFTSM verify that the employed of PID sliding surface combined with NFTSM has improved the transient responses and reduced the steady state error of the system. The proposed PID-NFTSM and Adaptive-Fuzzy PID-NFTSM controllers impose the system converged very fast, low oscillation and low steady state error. However, the disadvantages of the PID-NFTSM and Adaptive Fuzzy PID-NFTSM are that the computational times are higher, $0.90(\mathrm{~s})$ and 1.21(s) compared to 0.83(s), 0.88(s) and $0.81(\mathrm{~s})$ of the NFTSM, FOSM and TOSM, respectively, as shown in Table IV (column 5). However, as compared to the simple PID controller (the computational time of the PID controller is 0.70 as shown in Table IV), which is known as one of the simplest control methods, the proposed approaches, PID-NFTSM (0.90) and Adaptive Fuzzy PID-NFTSM (1.21), provide acceptable computational burdens. Therefore, it is potential to implement the proposed algorithms in real-time practical applications.

Fig. 4 shows the velocity tracking performance of the five controllers. It is obvious to see that the proposed PID-NFTSM and Adaptive Fuzzy PID-NFTSM controllers provide better performances compared to the NFTSM, FOSM and TOSM controllers. The continuous control inputs of the proposed PIDNFTSM and Adaptive Fuzzy PID-NFTSM compared to other controllers are shown in Fig. 5. It can be seen from the Fig. 5 that the control inputs of the Adaptive Fuzzy PID-NFTSM are smoother compared to the PID-NFTSM, NFTSM, FOSM and TOSM. This result verifies the benefit of the employed of fuzzy logic into the PID-NFTSM as discussed in Remark 3. From the reported results above, we can conclude that the proposed Adaptive Fuzzy PID-NFTSM is the best in term of transient response, tracking accuracy, chattering elimination and no requirement of prior knowledge of the uncertainties and faults information.

Remark 4: The elapsed time used in Table IV in this paper is the time that Matlab is used to complete 30second simulation time. This may not reflect the true computational burden of the controllers but it can be used to provide a general idea about the comparison in computational time among controllers.

Remark 5: In this paper, we design a robust FTC to compensate for the effects of actuator or component faults only. The proposed method may not be able to compensate for the sensor faults. The sensor faults detection and compensation will be investigated in our future work.

\section{CONCLUSIONS}

This paper develops a novel adaptive fuzzy PID-NFTSM controller for robust fault tolerant control of a class of secondorder uncertainty nonlinear systems to obtain high performance of fault tolerant control system. The integration between PID and NFTSM is significant since it improves the robustness and transient response of the system a lot, while preserving the great features of the NFTSM such as lower tracking error and defined finite time convergence. In addition, this integration provides a full order control system and therefore the chattering is reduced as the same manner to FOSM. The employed of the fuzzy logic could help to eliminate the need of the prior knowledge of the uncertainties and faults and reduce the chattering as well. The stability of the whole hybrid system is guaranteed based on Lyapunov criteria. The proposed approach is applied for attitude control of a spacecraft, and the simulation results verify that the proposed approach provides very fast transient response, lower steady state error, fast convergence and less chattering.

In the future works, we will study the effects of the controller parameters such as the adaptive gains to the performance of the system and verify the performance of the designed controllers in practical experiments. We will also investigate the effects of the sensors faults in the controller system.

\section{REFERENCES}

[1] M. Van and H. J. Kang, "Bearing Defect Classification Based on Individual Wavelet Local Fisher Discriminant Analysis with Particle Swarm Optimization," IEEE Transactions on Industrial Informatics, vol. 12, no. 1, pp. 124-135, Feb. 2016.

[2] M. Van, D. Wu, S. S. Ge and H. Ren, "Fault Diagnosis in Image-Based Visual Servoing With Eye-in-Hand Configurations Using Kalman Filter," IEEE Transactions on Industrial Informatics, vol. 12, no. 6, pp. 1998-2007, Dec. 2016.

[3] R. Nazari, M. M. Seron, J. A. D. Dona, "Actuator fault tolerant control of systems with polytopic uncertainties using set-based diagnosis and virtualactuator-based reconfiguration," Automatica, vol. 75, pp. 182-190, 2017.

[4] M. Van, H. J. Kang, "A robust fault diagnosis and accommodation scheme for robot manipulators," International Journal of Control, Automation and Systems, vol. 11, no. 2, pp. 377-388, 2013. 
[5] Y. Li, Z. Ma, S. Tong, "Adaptive Fuzzy Output-Constrained FaultTolerant Control of Nonlinear Stochastic Large-Scale Systems With Actuator Faults," IEEE Transactions on Cybernetics, vol. 47, no. 9, pp. 2362-2376, 2017.

[6] X. He, Z. Wang, L. Qin and D. Zhou, "Active Fault-Tolerant Control for an Internet-Based Networked Three-Tank System," IEEE Transactions on Control Systems Technology, vol. 24, no. 6, pp. 2150-2157, Nov. 2016.

[7] M. Van, S. S. Ge, D. Ceglarek, "Fault Estimation and Accommodation for Virtual Sensor Bias Fault in Image-Based Visual Servoing using Particle Filter," IEEE Transactions on Industrial Informatics, vol.PP, no.99, pp.1-1 doi: 10.1109/TII.2017.2723930, to be published.

[8] G. Zhang, H. Zhang, X. Huang, J. Wang, H. Yu and R. Graaf, "Active Fault-Tolerant Control for Electric Vehicles With Independently Driven Rear In-Wheel Motors Against Certain Actuator Faults," IEEE Transactions on Control Systems Technology, vol. 24, no. 5, pp. 15571572, Sept. 2016.

[9] M. Van, H. J. Kang, Y. S. Suh, K. S. Shin, "A robust fault diagnosis and accommodation scheme for robot manipulators, International Journal of Control, Automation and Systems, vol. 11, no. 2, pp. 377-388, 2013.

[10] Q. Hu, X. Shao and L. Guo, "Adaptive Fault-Tolerant Attitude Tracking Control of Spacecraft with Prescribed Performance," IEEE/ASME Transactions on Mechatronics, vol. 23, no. 1, pp. 331-341, 2018.

[11] L. I. Allerhand and U. Shaked, "Robust Switching-Based Fault Tolerant Control," IEEE Transactions on Automatic Control, vol. 60, no. 8, pp. 2272-2276, Aug. 2015.

[12] N. Alibeji, N. Sharma, "A PID-Type Robust Input Delay Compensation Method for Uncertain Euler-Lagrange Systems," IEEE Transactions on Control Systems Technology, vol. 25, no. 6, pp. 2235-2242, 2017.

[13] Y. Song, X. Huang, C. Wen, "Robust Adaptive Fault-tolerant PID Control of MIMO Nonlinear Systems with Unknown Control Direction," IEEE Transactions on Industrial Electronics, vol. 64, no. 6, pp. 4876-4884, 2017.

[14] Y. D. Song, J. Guo, "Neuro-adaptive Fault-tolerant Tracking Control of Lagrange Systems Pursuing Targets with Unknown Trajectory," IEEE Transactions on Industrial Electronics, vol. 64, no. 5, pp. 3913-3920, 2017.

[15] S. Tong, T. Wang and Y. Li, "Fuzzy Adaptive Actuator Failure Compensation Control of Uncertain Stochastic Nonlinear Systems With Unmodeled Dynamics," IEEE Transactions on Fuzzy Systems, vol. 22, no. 3, pp. 563-574, June 2014.

[16] E. Kamal, A. Aitouche, R. Ghorbani and M. Bayart, "Robust Fuzzy FaultTolerant Control of Wind Energy Conversion Systems Subject to Sensor Faults," IEEE Transactions on Sustainable Energy, vol. 3, no. 2, pp. 231241, April 2012.

[17] V. Utkin, Sliding Modes on control and Optimization, Springer Verlag, Berlin, Germany, 1992.

[18] H. Alwi and C. Edwards, "Fault Detection and Fault-Tolerant Control of a Civil Aircraft Using a Sliding-Mode-Based Scheme," IEEE Transactions on Control Systems Technology, vol. 16, no. 3, pp. 499510, May 2008.

[19] S. Islam and X. P. Liu, "Robust Sliding Mode Control for Robot Manipulators," IEEE Transactions on Industrial Electronics, vol. 58, no. 6, pp. 2444-2453, June 2011.

[20] Y. Chang, "Adaptive Sliding Mode Control of Multi-Input Nonlinear Systems With Perturbations to Achieve Asymptotical Stability," IEEE Transactions on Automatic Control, vol. 54, no. 12, pp. 2863-2869, Dec. 2009.

[21] S. Wen, M. Z. Q. Chen, Z. Zeng, T. Huang, C. Li, "Adaptive NeuralFuzzy Sliding-Mode Fault-Tolerant Control for Uncertain Nonlinear Systems," IEEE Transactions on Systems, Man, and Cybernetics: Systems, vol. 47, no. 8, pp. 2268-2278, 2017.

[22] Q. Meng, T. Zhang, X. Gao and J. Y. Song, "Adaptive Sliding Mode Fault-Tolerant Control of the Uncertain Stewart Platform Based on Offline Multibody Dynamics," IEEE/ASME Transactions on Mechatronics, vol. 19, no. 3, pp. 882-894, June 2014.

[23] Y. W. Liang, S. D. Xu, and C. L. Tsai, "Study of VSC reliable designs with application to spacecraft attitude stabilization," IEEE Transactions on Control Systems Technology, vol. 15, no. 2, pp. 332-338, 2007.

[24] B. Xiao, Q. Hu and Y. Zhang, "Adaptive Sliding Mode Fault Tolerant Attitude Tracking Control for Flexible Spacecraft Under Actuator
Saturation," IEEE Transactions on Control Systems Technology, vol. 20, no. 6, pp. 1605-1612, Nov. 2012.

[25] H. Wang et al., "Design and Implementation of Adaptive Terminal Sliding-Mode Control on a Steer-by-Wire Equipped Road Vehicle," IEEE Transactions on Industrial Electronics, vol. 63, no. 9, pp. 57745785, Sept. 2016.

[26] L. Wang, T. Chai and L. Zhai, "Neural-Network-Based Terminal SlidingMode Control of Robotic Manipulators Including Actuator Dynamics," IEEE Transactions on Industrial Electronics, vol. 56, no. 9, pp. 32963304, Sept. 2009.

[27] C. U. Solis, J. B. Clempner and A. S. Poznyak, "Fast Terminal SlidingMode Control With an Integral Filter Applied to a Van Der Pol Oscillator," IEEE Transactions on Industrial Electronics, vol. 64, no. 7, pp. 5622-5628, July 2017.

[28] J. Ni, L. Liu, C. Liu, X. Hu and S. Li, "Fast Fixed-Time Nonsingular Terminal Sliding Mode Control and Its Application to Chaos Suppression in Power System," IEEE Transactions on Circuits and Systems II: Express Briefs, vol. 64, no. 2, pp. 151-155, Feb. 2017.

[29] L. Yang and J. Yang, "Nonsingular fast terminal sliding-mode control for nonlinear dynamical systems," Int. J. Robust Nonlin. Control, vol. 21, no. 16, pp. 1865-1879, 2011.

[30] J. Zheng, H, Wang, Z. Man, J. Jin and M. Fu, "Robust motion control of a linear motor positioner using fast nonsingular terminal sliding mode," IEEE/ASME Transactions on Mechatronics, vol. 20, no.4, pp. 17431752, 2015.

[31] S. S. D. Xu, C. C. Chen and Z. L. Wu, "Study of Nonsingular Fast Terminal Sliding-Mode Fault-Tolerant Control," IEEE Transactions on Industrial Electronics, vol. 62, no. 6, pp. 3906-3913, June 2015.

[32] M. Van, S. S. Ge, H. Ren, "Finite Time Fault Tolerant Control for Robot Manipulators Using Time Delay Estimation and Continuous Nonsingular Fast Terminal Sliding Mode Control," IEEE Transactions on Cybernetics, vol.47, no. 7, pp. 1681-1693, 2017.

[33] V. Parra-Vega, S. Arimito, Y.-H. Liu, G. Hirzinger, and P. Akella, "Dynamic sliding PID control for tracking of robot manipulators: Theory and experiments," IEEE Transactions on Robotics and Automation, vol. 19, no. 6, pp. 967-976, Dec. 2003.

[34] Y. Li, Q. Xu, "Adaptive sliding mode control with pertubation estimation and PID sliding surface for motion tracking of a piezo-driven micromanipulator," IEEE Transactions on Control Systems Technology, vol. 18, no. 4, pp. 798-810, July 2010.

[35] J. Y. Peng and X. B. Chen, "Integrated PID-based sliding mode state estimation and control for piezoelectric actuators," IEEE/ASME Transactions on Mechatronics, vol. 19, no. 1, pp. 88-99, Feb. 2014.

[36] Y. Cao and X. B. Chen, "An output tracking based discrete PID-sliding mode control for MIMO systems," IEEE/ASME Transactions on Mechatronics, vol. 19, no. 4, pp. 1183-1194, 2014.

[37] J. Qin, Q. Ma, H. Gao and W. X. Zheng, "Fault-Tolerant Cooperative Tracking Control via Integral Sliding Mode Control Technique," IEEE/ASME Transactions on Mechatronics, vol. 23, no. 1, pp.342-351, 2018.

[38] M. Van, S. S. Ge, H. Ren, "Robust Fault-Tolerant Control for a Class of Second-Order Nonlinear Systems Using an Adaptive Third-Order Sliding Mode Control," IEEE Transactions on Systems, Man, and Cybernetics: Systems, vol. 47, no. 2, pp. 221-228, 2017.

[39] Y. Cao and X. B. Chen, "Disturbance-observer-based sliding-mode control for a 3-DOF nanopositioning stage," IEEE/ASME Transactions on Mechatronics, vol. 19, no. 3, pp. 924-931, Jun. 2014.

[40] G. Bartolini, A. Ferrara, E. Usani, "Chattering avoidance by second-order sliding mode control," IEEE Transactions on Automatic Control, vol.43, no.2, pp.241-246, 1998.

[41] M. Van, H. J. Kang, Y. S. Suh, "Second order sliding mode based output feedback tracking control for uncertain robot manipulators," International Journal of Advanced Robotic Systems, vol. 10, no. 1, pp. 1-9, 2013.

[42] M. Van, H. J. Kang, K. S. Shin, "Backstepping quasi-continuous highorder sliding mode control for a T-S fuzzy system with an application for a two-link robot control," Proceeding of the institution of Mechanical Engineers, Part C: Journal of Mechanical Engineering, vol. 228, no. 6, pp. 1488-1500, 2014.

[43] M. Van, H. J. Kang, "Robust fault tolerant control for uncertain robot manipulators based on adaptive quasi-continuous high-order sliding mode and neural network," Proceeding of the institution of Mechanical Engineers, Part C: Journal of Mechanical Engineering, vol. 229, no. 8, pp. 1425-1446, 2015. 
[44] Y. Feng, X. Yu, F. Han, "High-order terminal sliding mode observer for parameter estimation of a permanent-magnet synchronous motor," IEEE Transactions on Industrial Electronics, vol. 60, no. 10, pp. 4272-4280, 2013.

[45] A. Levant, "Robust exact differentiation via sliding mode technique," Automatica, vol. 34, no. 3, pp. 379-384, 1998.

[46] Y. Feng, F. Han, X. Yu, Chattering free full-order sliding mode control, Automatica, vol. 50, pp. 1310-1314, 2014.

[47] J. Liu, H. Li, Y. Deng, "Torque ripple minimization of PMSM based on robust ILC via adaptive sliding mode control," IEEE Transactions on Power Electronics, vol. 33, no. 4, pp. 3655-3671, 2018.

[48] H. Li, P. Shi, D. Yao, "Adaptive sliding mode control of Markov Jump Nonlinear Systems with Actuator Faults," IEEE Transactions on Automatic Control, vol. 62, no. 4, pp. 1933-1939, 2017.

[49] Y. Zhang, Q. Xu, "Adaptive sliding mode control with parameter estimation and Kalman filter for precision control of a Piezo-Driven Microgripper, IEEE Transactions on Control System Technology, vol. 25, no. 2, pp. 728-735, 2017.

[50] G. P. Incremona, M. Cucuzzella, A. Ferrara, "Adaptive suboptimal second-order sliding mode control for microgrids," International Journal of Control, vol. 89, no. 9, pp. 1849-1867, 2016.

[51] C. Edwards, Y. Shtessel, "Adaptive continuous higher order sliding mode control," Automatica, vol. 65, pp. 183-190, 2016.

[52] X. Zhao, X. Wang, G. Zong, X. Zheng, "Adaptive Neural Tracking Control for Switched High-Order Stochastic Nonlinear Systems," IEEE Transactions on Cybernetics, vol. 47, no. 10, pp. 3088-3099, 2017.

[53] W. Bian and X. Chen, "Neural Network for Nonsmooth, Nonconvex Constrained Minimization Via Smooth Approximation," IEEE Transactions on Neural Networks and Learning Systems, vol. 25, no. 3, pp. 545-556, March 2014.

[54] Z. Li, Y. Xia, D. Wang, D. H. Zhai, C. Y. Su and X. Zhao, "Neural Network-Based Control of Networked Trilateral Teleoperation With Geometrically Unknown Constraints," IEEE Transactions on Cybernetics, vol. 46, no. 5, pp. 1051-1064, May 2016.

[55] S. Yin, H. Gao, J. Qiu, O. Kaynak, "Adaptive Fault-Tolerant Control for Nonlinear System With Unknown Control Directions Based on Fuzzy Approximation," IEEE Transactions on Systems, Man, and Cybernetics: Systems, vol.47, no. 8, pp. 1909-1918, 2017.

[56] D. Zhai, L. An, J. Dong, Q. Zhang, "Switched Adaptive Fuzzy Tracking Control for a Class of Switched Nonlinear Systems under Arbitrary Switching," IEEE Transactions on Fuzzy Systems , vol.PP, no.99, pp.1-1, doi: 10.1109/TFUZZ.2017.2686378.

[57] C. E. Castaneda, A. G. Loukianov, E. N. Sanchez and B. Castillo-Toledo, "Discrete-Time Neural Sliding-Mode Block Control for a DC Motor With Controlled Flux," IEEE Transactions on Industrial Electronics, vol. 59, no. 2, pp. 1194-1207, Feb. 2012.

[58] B. S. Park, S. J. Yoo, J. B. Park and Y. H. Choi, "Adaptive Neural Sliding Mode Control of Nonholonomic Wheeled Mobile Robots With Model Uncertainty," IEEE Transactions on Control Systems Technology, vol. 17, no. 1, pp. 207-214, Jan. 2009.

[59] S. Wen, M. Z. Q. Chen, Z. Zeng, T. Huang and C. Li, "Adaptive NeuralFuzzy Sliding-Mode Fault-Tolerant Control for Uncertain Nonlinear Systems," IEEE Transactions on Systems, Man, and Cybernetics: Systems, vol. 47, no. 8, pp. 2268-2278, Aug. 2017.

[60] R. J. Wai and R. Muthusamy, "Fuzzy-Neural-Network Inherited SlidingMode Control for Robot Manipulator Including Actuator Dynamics," IEEE Transactions on Neural Networks and Learning Systems, vol. 24, no. 2, pp. 274-287, Feb. 2013.

[61] J. Zhang, Y. Lin and G. Feng, "Analysis and Synthesis of Memory-Based Fuzzy Sliding Mode Controllers," IEEE Transactions on Cybernetics, vol. 45, no. 12, pp. 2880-2889, Dec. 2015.

[62] T. H. Ho and K. K. Ahn, "Speed Control of a Hydraulic Pressure Coupling Drive Using an Adaptive Fuzzy Sliding-Mode Control," IEEE/ASME Transactions on Mechatronics, vol. 17, no. 5, pp. 976-986, Oct. 2012.

[63] R. Shahnazi, H. M. Shanechi and N. Pariz, "Position Control of Induction and DC Servomotors: A Novel Adaptive Fuzzy PI Sliding Mode Control," IEEE Transactions on Energy Conversion, vol. 23, no. 1, pp. 138-147, March 2008.

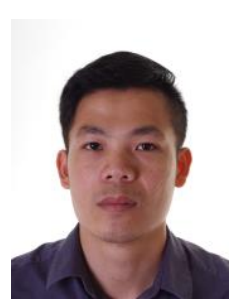

Mien Van received his B.S. degree in Electrical Engineering from Danang University of Technology, DaNang city, Vietnam, in 2009. He received his Ph.D. degree in the School of Electrical Engineering, University of Ulsan, South Korea in 2015.

He has been a Postdoctoral Research Fellow with the Advanced Robotics Centre, Faculty of Engineering, National University of Singapore, Singapore, and the WMG, University of Warwick, Coventry, U.K., and an Independent Research Fellow/Lecturer with Nottingham Trent University, Nottingham, U.K., since 2015. From 2018, he will be a Senior Research Fellow with the College of Engineering, Mathematics and Physical Sciences, University of Exeter, Exeter, U.K. His current research interests include assistive robotics, robot control, robot-vision systems, fault diagnosis and fault tolerant, machine learning, and sensing and perception.

Dr. Van was a recipient of the IET Science, Measurement and Technology Premium Awards in 2017. 